\title{
Safety and efficacy of high-dose intravenous iron carboxymaltose vs. iron sucrose for treatment of postpartum anemia
}

\author{
Anita Pfenniger, Christine Schuller, \\ Patricia Christoph and Daniel Surbek* \\ Department of Obstetrics and Gynecology, University \\ Hospital Bern, University of Bern, Bern, Switzerland
}

\begin{abstract}
Objective: The purpose of this study is to compare the safety and efficacy of intravenous (IV) high-dose iron carboxymaltose (ICM) with iron sucrose (IS) for the treatment of postpartum anemia.

Study design: We performed a retrospective cohort study with 210 anemic inpatient women in the postpartum period who received IV high-dose ICM (15 mg/kg; maximum, $1000 \mathrm{mg}$ ) or IS $(2 \times 200 \mathrm{mg})$, respectively. Safety and tolerability of both groups were compared on the basis of reported systemic and local adverse events. The cohorts were matched for baseline characteristics and their initial hemoglobin $(\mathrm{Hb})$ values. The secondary endpoint included drug efficacy assessment by measurement of $\mathrm{Hb}$ level increase up to 8 days after treatment.

Results: Rapid administration of high ICM doses was as well tolerated as IS with overall adverse events of 5\% (ICM) vs. $6 \%$ (IS). The most common complaint was burning and pain at the injection site. ICM was as effective as IS in changing $\mathrm{Hb}$ levels from the baseline. There was no difference in the mean daily $\mathrm{Hb}$ increase between the groups. Women with severe anemia showed the most effective responsiveness.

Conclusions: IV ICM is as safe as IS in the management of postpartum (IDA) iron deficiency anemia despite five times of higher dosage. Both drugs are effective and offer a rapid normalization of $\mathrm{Hb}$ after delivery. The single application of ICM shows advantages of lower incidence of side effects at the injection site, a shorter treatment period, and better patient compliance.
\end{abstract}

Keywords: Ferinject ${ }^{\oplus}$; hemoglobin; iron carboxymaltose; iron sucrose; parenteral iron substitution; Venofer ${ }^{\circledR}$ postpartum anemia.

\footnotetext{
*Corresponding author:

Prof. Daniel Surbek, MD

Department of Obstetrics and Gynecology

University Hospital Insel

Effingerstrasse 102

CH-3010 Bern

Switzerland

Tel.: +41316321103

Fax: +41316321105

E-mail: daniel.surbek@insel.ch
}

\section{Introduction}

The World Health Organization defines anemia as a hemoglobin $(\mathrm{Hb})<120 \mathrm{~g} / \mathrm{L}$ in women and $130 \mathrm{~g} / \mathrm{L}$ in men. For children and pregnant women, the limit is set by $110 \mathrm{~g} / \mathrm{L}[3,4,9,24$, $25,31]$. In developed countries, anemia is often found among children and pregnant women. Their iron requirement makes these groups more vulnerable to the typical iron deficiency anemia (IDA) with hypochromic, microcytic erythrocytes and low ferritin values [7, 25]. Data from the National Health and Nutrition Examination Survey [8] indicate that IDA is prevalent in $4.2 \%$ of all postpartum US women aged $20-40$ years.

Iron deficiency is the most common cause of anemia $[3,4,9$, $13,24,31]$ and is associated with a variety of coexisting conditions. Its general health effects include various symptoms such as fatigue, headaches, dizziness, breathlessness, palpitations, reduced cognitive functions, and depression [6, 9, 24, 34].

Postpartum IDA is caused primarily by inadequate iron intake before pregnancy and by peripartum blood loss $[31,35]$. It affects low-income and minority women disproportionately $[5,7,8]$. It may impose a substantial disease burden during a critical period of maternal-infant interactions and can be very debilitating, especially when caring for a newborn [6, 24, 31, 35]. Furthermore, anemic puerperia have a longer average length of hospital stay, are more likely to receive a blood transfusion, and incur higher hospitalization costs [3, 13, 31]. Hence, postpartum IDA requires our attention and high-quality care.

Treatment of IDA involves identifying and treating the cause of the condition as well as replacing iron [3, 24]. The most reliable parameter to assert postpartum IDA is $\mathrm{Hb}$, because ferritin levels may vary and indicate false elevated values after delivery [22]. The treatment depends on the severity of the case and the woman's state of health. The recommended treatment for mild IDA $(\mathrm{Hb}>95 \mathrm{~g} / \mathrm{L})$ consists in oral administration of $80-200 \mathrm{mg}$ of iron (II) salts or iron (III) polymaltose, with the alternative of intravenous (IV) treatment in case of bad compliance or gastrointestinal intolerance. For more severe IDA $(\mathrm{Hb}<95 \mathrm{~g} / \mathrm{L})$, parenteral administration of iron is recommended [4, 18, 25, 32].

Although iron therapy is indicated in the anemia patient, both oral iron agents and currently available IV iron agents pose their challenges. Oral iron intake is limited by gastrointestinal complaints and patient non adherence $[1,3,17$, 35]. To overcome these problems, we used a number of IV preparations [e.g., iron dextran, sodium ferric gluconate, or iron sucrose (IS)]. However, the latter either require multiple administrations of low doses to replenish stores (sodium ferric gluconate and IS) or are associated with hypersensitivity reactions (iron dextran, 1.2\%) [1, 17, 24, 35]. 
Therefore, responding to the need for a novel preparation able to rapidly replenish iron stores with large iron doses and minimal risks of hypersensitivity or other adverse effects, iron carboxymaltose (ICM) (Ferinject ${ }^{\circledR}$ ) was developed and approved in 2008 as new IV treatment option in the majority of European countries [22].

The safety and efficacy of ICM in the treatment of postpartum IDA have been tested in a number of randomized, multicenter studies [3, 4, 6, 13-17, 23, 29, 31-35]. It was always compared with oral iron agents and demonstrated an outstanding safety profile combined with good effectiveness. ICM overcame the gastrointestinal limitations of oral treatment. Furthermore, through single administration, it offered many practical benefits such as greater patient comfort and compliance, shorter hospitalization time, and finally, cost reduction.

With the exception of one trial in chronic kidney patients undergoing hemodialysis [20], comparative trials of ICM and other IV formulations are still lacking. The aim of the current study was therefore to compare two IV iron agents, ICM and IS, for the treatment of postpartum anemia. The choice of IS as comparator was made because of its general acceptance as standard of care in the treatment of postpartum IDA. Based on the results of the above-quoted studies, we hypothesized that ICM is as safe and tolerable as IS despite five times of higher dosage. Even though the schedule foresees a single application of ICM, we assume that the hematologic responsiveness equals the one induced by IS.

\section{Material and methods}

\section{Study design and population}

This retrospective, exploratory cohort study was conducted at the University Women's Hospital in Bern, Switzerland. A total of 210 patients with postpartum IDA requiring IV iron supplementation were included. The inclusion criteria were women with an $\mathrm{Hb}<95$ $\mathrm{g} / \mathrm{L}(\mathrm{n}=200,95.23 \%)$, anemic patients with $>95 \mathrm{~g} / \mathrm{L}$ and intolerance of oral iron medication, insufficient $\mathrm{Hb}$ increase after oral treatment, or need to replenish iron stores rapidly. To assure statistical comparability, we matched the two arms of the study population as regards demographic baseline characteristics $\mathrm{Hb}$ value at baseline and confounders such as severe birth complications (preeclampsia/HELLP) and additive therapies [erythropoietin, blood transfusion, fresh frozen plasma (FFP)]. The $\mathrm{Hb}$ values before therapy were $81.98 \pm 10.91 \mathrm{~g} / \mathrm{L}$ in the ICM cohort and $80.11 \pm 10.3 \mathrm{~g} / \mathrm{L}$ in the IS arm, respectively $(\mathrm{P}=0.19)$. Thus, we enrolled 105 women treated with ICM $(15 \mathrm{mg} /$ $\mathrm{kg}$; maximum, $1000 \mathrm{mg}$ over $15 \mathrm{~min}$, almost all women receiving the maximum dose) over the years 2008-2010. The comparative group comprised 105 women who had received IS $(2 \times 200 \mathrm{mg}$ at 2 days' interval) in the years 2005-2008 before introduction of ICM in clinical routine care. All women with a history of anemia other than iron deficiency or blood loss were excluded (e.g., vitamin B12/folate-deficiency anemia, hemoglobinopathy, hemolytic anemia, tumor anemia).

In our inpatient postpartum study population, the primary outcome was to assess safety and tolerability of ICM compared with IS on the basis of adverse events that were spontaneously reported, elicited, or observed by the nurse or midwife during or after administration of the study drug. The routine clinical treatment protocol includes surveillance of the patient during and after IV iron administration and meticulous documentation of any abnormal signs or symptoms.
Therefore, despite the retrospective design, we assume the most reliable reports of adverse events by the medical staff, because IV iron infusions are closely documented on a specific monitoring sheet. Our secondary outcome included the record of $\mathrm{Hb}$ increase from baseline from onset of the treatment up to dismissal of the patients (maximum, 8 days). In each of the study groups, two cases with follow-up data after a surveillance of a maximum of 47 and 60 days, respectively, were also enclosed.

In order to assess potential effects of the study drug in particular clinical conditions, subgroup analysis was carried out on patients with peripartum complications (preeclampsia/HELLP syndrome or severe postpartum hemorrhage with $\mathrm{Hb}<75 \mathrm{~g} / \mathrm{L}$ ) or receiving additional therapy to the iron supplementation [allogeneic blood transfusion/FFP or erythropoiesis-stimulating agent (ESA)].

\section{Statistical analysis}

All subgroups passed the normality test, thus allowing a statistical correct matching of the study participants, despite the restricted number (e.g., in the substudy preeclampsia/HELLP syndrome). We especially checked for compatibility of baseline $\mathrm{Hb}$ of the two cohorts previous to treatment using the two-tailed Mann-Whitney $U$-test. Passing this normality test was the reason for setting the limit to 75 $\mathrm{g} / \mathrm{L}$ in the substudy with severe anemia women. In the analysis of our safety endpoint, we compared categorical variables of adverse events using the two-sided Fisher's exact test, which we preferred over the $\chi^{2}$-test because of the small number of reported adverse events. To assess for efficacy, we verified the statistical significance of betweengroup differences in $\mathrm{Hb}$ increase by applying the unpaired Welchcorrected $t$-test (two-tailed P-value) for continuous parameters. For all analyses, $\mathrm{P}$-values $<0.05$ were considered statistically significant. All tests were executed using the software programs Excel and Graph Pad InStat for Microsoft software, Inc., La Jolla, CA, USA.

\section{Results}

Demographic and clinical characteristics of the study participants are displayed in Table 1. No major differences between the groups were detected.

\section{Tolerability}

Both ICM and IS were very well tolerated, with an overall incidence of drug-related adverse events of $4.8 \%$ in the ICM and $5.7 \%$ in the IS group (Table 2). Most of them were mild to moderate. The highest incidence was registered in local burning and pain at the infusion site (1.9\% vs. $3.8 \%)$.

Three patients of the ICM group experienced systemic manifestations such as headache, sensation of heat, and short shivering. However, blood pressure remained normal, and there was no sign of anaphylaxis. In the IS group, one patient complained about fatigue and one about alteration of taste. The between-group difference was not statistically significant. No severe safety concern (e.g., hypersensitivity, anaphylaxis) occurred in either treatment groups.

\section{Efficacy}

The response rates of $\mathrm{Hb}$ are listed in Table 3. In the ICM group, the mean $\mathrm{Hb}$ levels increased from $81.9 \mathrm{~g} / \mathrm{L}$ at baseline 
Table 1 Demographic and baseline characteristics of participants (matched cohorts).

\begin{tabular}{|c|c|c|c|}
\hline & $\begin{array}{l}\text { ICM } \\
(n=105)\end{array}$ & $\begin{array}{l}\text { IS } \\
(n=105)\end{array}$ & P-value \\
\hline \multicolumn{4}{|l|}{$\mathrm{Hb}$ before therapy $(\mathrm{g} / \mathrm{L})$} \\
\hline Mean \pm SD & $81.9 \pm 10.9$ & $80.1 \pm 10.0$ & \multirow[t]{2}{*}{0.19} \\
\hline Range & $50-110$ & $48-96$ & \\
\hline \multicolumn{4}{|l|}{ Age (years) } \\
\hline Mean \pm SD & $30.5 \pm 6.2$ & $32.0 \pm 5.3$ & \multirow[t]{2}{*}{0.65} \\
\hline Range & $16-43$ & $17-45$ & \\
\hline \multicolumn{4}{|l|}{ Gravidity } \\
\hline Mean \pm SD & $1.9 \pm 1.1$ & $2.0 \pm 1.4$ & \multirow[t]{2}{*}{0.97} \\
\hline Range & $1-6$ & $1-8$ & \\
\hline \multicolumn{4}{|l|}{ Parity } \\
\hline Mean \pm SD & $1.7 \pm 0.9$ & $1.5 \pm 1.0$ & \multirow[t]{2}{*}{0.17} \\
\hline Range & $1-5$ & $1-6$ & \\
\hline \multicolumn{4}{|l|}{ Delivery method [n (\%)] } \\
\hline Vaginal & $31(29.5 \%)$ & $30(28.6 \%)$ & 1.00 \\
\hline Cesarean & $56(53.3 \%)$ & $58(55.2 \%)$ & 0.89 \\
\hline Forceps & $2(1.9 \%)$ & $4(3.8 \%)$ & 0.68 \\
\hline Vacuum & $16(15.2 \%)$ & $13(12.4 \%)$ & 0.69 \\
\hline \multicolumn{4}{|l|}{ Confounding factors [n (\%)] } \\
\hline \multicolumn{4}{|l|}{ Complication of delivery } \\
\hline Preeclampsia/HELLP & $11(10.5 \%)$ & $12(11.4 \%)$ & 1.00 \\
\hline Severe anemia & $25(23.8 \%)$ & $24(22.9 \%)$ & 1.00 \\
\hline \multicolumn{4}{|l|}{ Additive therapy } \\
\hline Erythropoietin & $19(18.1 \%)$ & $21(20.0 \%)$ & 0.86 \\
\hline Blood transfusion (FFP) & $19(18.1 \%)$ & $18(17.1 \%)$ & 1.00 \\
\hline
\end{tabular}

to $92.2 \mathrm{~g} / \mathrm{L}$ after an average control interval of 4.3 days. In the IS population, it increased from $80.1 \mathrm{~g} / \mathrm{L}$ to $88.2 \mathrm{~g} / \mathrm{L}$ after 3.9 days. The calculated daily increase was $3.3 \mathrm{~g} / \mathrm{L}$ and $4.1 \mathrm{~g} / \mathrm{L}$, respectively. There was no between-group difference in terms of absolute or daily $\mathrm{Hb}$ changes $(\mathrm{P}=0.26$ and $\mathrm{P}=0.89)$.

Graphic 1 illustrates the course of $\mathrm{Hb}$ response rate at the time point of 2,5 , and 8 days. In an initial phase, both groups showed great effectiveness (5.1 vs. $6.9 \mathrm{~g} / \mathrm{L}$ after only 2 days); at longer interval, however, ICM seemed to have a better and presumably more sustained effect on the hemoglobin value compared with IS (14.9 vs. $11.7 \mathrm{~g} / \mathrm{L}$ after 5 days, 18.3 vs. $5.3 \mathrm{~g} / \mathrm{L}$ after 8 days). Although absolute values went further apart the longer the interval from the onset of therapy, these between-group differences were not statistically significant at any time point $(\mathrm{P}=0.26$ by 2 days, $\mathrm{P}=0.38$ by 5 days, $\mathrm{P}=0.1$

Table 2 Drug-related adverse events.

\begin{tabular}{llll}
\hline & $\begin{array}{l}\text { ICM } \\
(\mathrm{n}=105)\end{array}$ & $\begin{array}{l}\text { IS } \\
(\mathrm{n}=105)\end{array}$ & P-value \\
\hline Total & $5(4.8 \%)$ & $6(5.7 \%)$ & 1.00 \\
Local pain & $2(1.9 \%)$ & $4(3.8 \%)$ & 0.68 \\
Systemic & $3(2.9 \%)$ & $2(1.9 \%)$ & 1.00 \\
Headache & $1(0.9 \%)$ & 0 & 1.00 \\
Sensation of heat & $1(0.9 \%)$ & 0 & 1.00 \\
Shivering & $1(0.9 \%)$ & 0 & 1.00 \\
Fatigue & 0 & $1(0.9 \%)$ & 1.00 \\
Alteration of taste & 0 & $1(0.9 \%)$ & 1.00 \\
\hline
\end{tabular}

by 8 days). Beyond 8 days, the response was associated with a further increase in the ICM group, whereas the curve of the IS group remained stable. This observation reflects a trend and is to be taken with caution however. The restricted number of patients observed at long-term did not allow for a reliable statistical statement.

\section{Subgroup: preeclampsia/HELLP syndrome}

Eleven and 12 patients experienced preeclampsia or fully developed HELLP syndrome in the ICM and IS group, respectively. The tolerability of these women was very good. Not a single adverse event was registered in either group. In the ICM population, the mean $\mathrm{Hb}$ levels increased from 81.0 $\mathrm{g} / \mathrm{L}$ at baseline to $98.9 \mathrm{~g} / \mathrm{L}$ after 5.8 days. In the comparison group, it improved from $78.8 \mathrm{~g} / \mathrm{L}$ to $87.4 \mathrm{~g} / \mathrm{L}$ after 3.5 days. Converted on a daily rate, the rise in Hb levels was 3.2 and 3.5 $\mathrm{g} / \mathrm{L}$ a day, respectively. The between-group difference was not significant $(\mathrm{P}=0.75)$.

\section{Subgroup: severe anemia}

The criteria for a severe anemia were fulfilled in 25 women treated with ICM and in 24 with IS. Two local drug reactions were registered in each group ( $8.0 \%$ vs. $8.3 \%)$. The mean $\mathrm{Hb}$ raised from $67.1 \mathrm{~g} / \mathrm{L}$ at baseline to $89.7 \mathrm{~g} / \mathrm{L}$ after 3.9 days (ICM), in contrast to $65.3-81.2 \mathrm{~g} / \mathrm{L}$ at an interval of 3 days (IS). The daily amounts were $6.0 \mathrm{~g} / \mathrm{L}$ a day compared with $6.9 \mathrm{~g} / \mathrm{L}$ a day, respectively. The difference was not significant $(\mathrm{P}=0.54)$.

\section{Subgroup: ESA}

Another subcategory was formed by 19 and 21 women treated with ESAs in addition to the iron treatment. On 4 days, 10,000 IE of erythropoietin were administered. The administration of ICM caused one local pain complaint $(5.3 \%)$ and a short shivering episode $(5.3 \%)$ in another woman. Application of IS did not provoke any drug-related reaction. This difference was not significant $(\mathrm{P}=0.22)$. A discrepancy was also observed regarding the therapy response. The mean $\mathrm{Hb}$ increased from $71.0 \mathrm{~g} / \mathrm{L}$ to $89.1 \mathrm{~g} / \mathrm{L}$ after an average of 3.7 days $(18.1$ $\mathrm{g} / \mathrm{L}$ ) in patients treated with ICM and from $71.3 \mathrm{~g} / \mathrm{L}$ to 78.9 $\mathrm{g} / \mathrm{L}$ after 2.4 days $(7.6 \mathrm{~g} / \mathrm{L})$ in women receiving $\mathrm{IS}$, respectively $(\mathrm{P}=0.023)$. This difference may be due to the uneven $\mathrm{Hb}$-control interval. The daily increase did not let any significant variation appear (5.0 vs. $4.6 \mathrm{~g} / \mathrm{L}$ a day, $\mathrm{P}=0.56$ ).

\section{Subgroup: blood transfusion}

Allogeneic donor blood transfusion was administered to 19 (ICM) and 18 (IS) women with severe clinical symptoms and very low $\mathrm{Hb}$ values. The administration dose ranged from 1 to 14 blood units, depending on the severity of the woman's state of health. Only one minor local pain at the infusion site was reported in both groups $(5.6 \%$ vs. 5.6\%). The mean $\mathrm{Hb}$ increased from $72.7 \mathrm{~g} / \mathrm{L}$ to $93.8 \mathrm{~g} / \mathrm{L}$ after 3.5 days in the ICM group and from $68.6 \mathrm{~g} / \mathrm{L}$ to $87.7 \mathrm{~g} / \mathrm{L}$ after 3.4 days in the IS 
Table 3 Efficacy parameter: response rates for $\mathrm{Hb}$.

\begin{tabular}{|c|c|c|c|c|c|c|c|}
\hline & \multicolumn{3}{|l|}{ ICM } & \multicolumn{3}{|l|}{ IS } & \multirow[t]{2}{*}{$\mathrm{P}$-value } \\
\hline & Mean \pm SD & Range & $95 \% \mathrm{CI}$ & Mean \pm SD & Range & $95 \% \mathrm{CI}$ & \\
\hline Hb before therapy $(\mathrm{g} / \mathrm{L})$ & $81.9 \pm 10.9$ & $50-110$ & $79.8-84.1$ & $80.1 \pm 10.0$ & $48-96$ & $78.2-82.1$ & 0.19 \\
\hline $\mathrm{Hb}$ after therapy $(\mathrm{g} / \mathrm{L})$ & $92.2 \pm 12.3$ & $70-138$ & $89.1-95.3$ & $88.2 \pm 12.1$ & $57-126$ & $85.3-91.2$ & 0.09 \\
\hline Control interval (days) & $4.3 \pm 5.9$ & $1-47$ & $2.8-5.8$ & $3.9 \pm 7.1$ & $1-60$ & $2.2-5.7$ & 0.24 \\
\hline Absolute $\mathrm{Hb}$ increase (g/L) & $12.9 \pm 14.3$ & -11 to 50 & $9.3-16.6$ & $9.3 \pm 11.9$ & -11 to 53 & $6.3-12.2$ & 0.26 \\
\hline Daily $\mathrm{Hb}$ increase (g/L/d) & $3.3 \pm 4.6$ & -7 to 21 & $2.1-4.5$ & $4.1 \pm 6.3$ & -5 to 38 & $2.5-5.7$ & 0.89 \\
\hline
\end{tabular}

group. Although the daily response rate was less effective in the ICM group (6.1 g/L a day) compared with the IS $(9.4 \mathrm{~g} / \mathrm{L}$ a day) group, it was not found to be of statistical significance $(\mathrm{P}=0.35)$.

\section{Discussion}

IV iron substitution is frequently used in the management of IDA postpartum. New iron preparations offer the possibility to treat with a large dose of IV iron in a single IV administration. Safety and tolerability of these new preparations are therefore important.

In terms of tolerability, both ICM and IS showed a very low overall incidence of drug-related adverse events $(4.8 \%$ vs. $5.7 \%, \mathrm{P}=1)$, most of them being local reactions on the injection site. A large number of other clinical trials conducted across a wide spectrum of indications for ICM support the results of our current investigation [1-4, 6, 13-19, 23, 24, $28,29,30-35]$. The overall incidence of adverse events in this literature was generally similar or higher than our findings $(5.4 \%$ [30], $10.6 \%$ [31], 9.3\% [3], 26\% [13]), and the risk of hypersensitivity or other serious drug reactions was minimal or neglectable also. Furthermore, no safety concerns were identified in breastfed infants of mothers receiving ICM [13]. To avoid hypotension and other dose-related adverse reactions, we limited administration of prior available IV iron agents to $100 \mathrm{mg}$ for iron dextran over $2 \mathrm{~min}, 125 \mathrm{mg}$ of ferric gluconate over $10 \mathrm{~min}$, or $200 \mathrm{mg}$ of IS over 2-5 min [35]. ICM can be administered $15 \mathrm{mg} / \mathrm{kg}$ and a maximum of $1000 \mathrm{mg}$ over $15 \mathrm{~min}$. Thus reducing the need for multiple

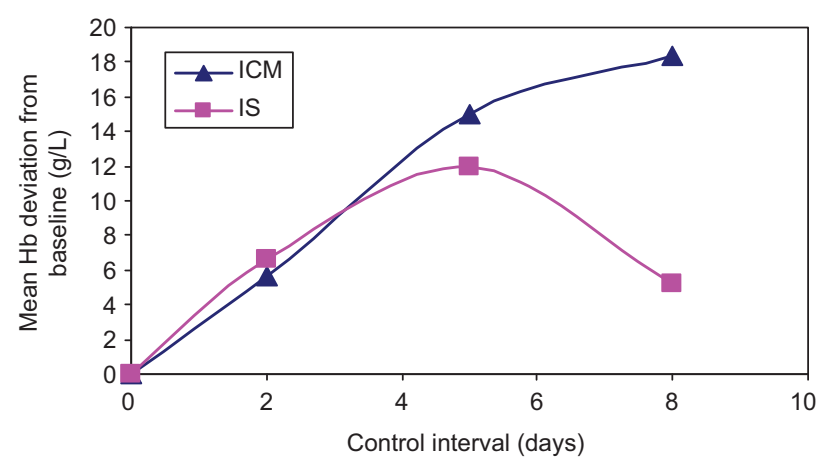

Graphic 1 Mean $\mathrm{Hb}$ deviation from baseline. infusions, ICM renders an ideal option for safe, rapid, and uncomplicated IV iron replenishment.

The only available trial so far [29] comparing ICM and IS directly was conducted on the setting of patients undergoing hemodialysis. It showed a lower proportion of ICM than IS recipients who experienced at least one drug-related adverse event.

Based on the change of $\mathrm{Hb}$, ICM and IS iron treatment were both effective in treating postpartum IDA. We found a considerable responsiveness especially during the first 5 days. There was no significant between-group difference at any registered time point. The mean daily increase was of 3.3 and $4.1 \mathrm{~g} / \mathrm{L}$ a day.

Our results validate several randomized, open-label, controlled, multicenter trials in postpartum patients where ICM was considered to be very effective in the treatment of IDA, most of them elaborated over a long-term follow-up of 12 weeks $[6,13,35]$. Other publications give an overview over the changes of $\mathrm{Hb}$ levels during the first few days after treatment with comparable results for IS [10, 26, 27].

The clinical advantage of ICM in the treatment of postpartum IDA is shown in other studies, especially when compared with oral treatment that did not prove to replenish iron stores sufficiently $[3,13,31]$.

The subgroup analysis in women with preeclampsia or HELLP syndrome, both with IV treatments, was associated with a very good tolerability and showed a similar $\mathrm{Hb}$ change compared with the overall population. No studies published to date on this very population were found to support our findings. We therefore assume that both ICM and IS can be considered as valuable drug options in the treatment of these special high-risk patients.

Patients with severe anemia showed a good tolerability, and the response rate was greatest in patients with the lowest $\mathrm{Hb}$ values, as reported in previous studies [13, 31, 35]. It exceeded thus considerably the rate measured in the overall study population. IV iron replacement is most advantageous in such patients, where rapid availability of iron is important to correct anemia. Sure enough, patients with more severe IDA are of particular concern, because they are at higher risk of recurrent IDA once menstruation restarts, and the iron deficit could be carried forward into subsequent pregnancies [13].

The combination of ESA and parenteral iron was well tolerated (overall adverse events, $10.5 \%$ vs. $0 \%, \mathrm{P}=0.22$ ), which is supported by the results of studies combining ICM and ESA [15] as well as IS and ESA [12, 21]. In terms of 
efficacy, combined application showed better results than single iron substitution (5.0 vs. $4.6 \mathrm{~g} / \mathrm{L}$ a day). We must make allowance, however, that this subgroup started with lower baseline $\mathrm{Hb}$ values, which can partly explain the greater hematologic responsiveness. In keeping with our results, it was demonstrated [11] that the vicious circle encountered in IDA (inhibited erythropoiesis, restricted iron availability, low erythropoietin serum levels) can be overcome by administrating the patients a combined therapy with ESA/IV iron. Yet, IDA should be corrected before initiation of ESA treatment, because insufficient iron availability can lead to hyporesponsiveness to ESA [28]. Good assessment for safety and efficacy of this combinative therapy is of great interest, because it is considered to be the therapeutic option in severely anemic women.

Women in need of blood transfusion with additional IV iron replacement showed a good tolerability, with only one reported injection site reaction in each group (5.6\%). Although the baseline Hb was comparable with the subgroup with severe anemia, the response rate with additive administration of blood units or FFP did not induce a significant greater $\mathrm{Hb}$ improvement (iron only, 6.0 vs. $6.9 \mathrm{~g} / \mathrm{L}$ a day; iron and blood transfusion/FFP, 6.1 vs. $9.4 \mathrm{~g} / \mathrm{L}$ a day, $\mathrm{P}=0.35$ ). In any case, either with or without blood transfusion, IV iron was efficient in correcting severe anemia. In a trial by Van Wyck et al. [34] with women receiving a large dose of ICM after heavy uterine bleeding, it was even shown that a mean ICM dose provided the iron required to produce the equivalent of five units of blood.

Some specific limitations of our study should be considered. First, although the four subgroups studied ascertain a good tolerability and efficacy, the small number of patients in the subgroups especially in women with preeclampsia/ HELLP syndrome ( $\mathrm{n}=11$ vs. 12 ) may not offer enough statistical power to reach sufficient evidence. Second, because of its retrospective nature, our study did not examine the effects of improving hematologic parameters such as ferritin or transferrin saturation, nor did it follow the women over a very longer period to assess for possible delayed adverse events or significant long-term changes in $\mathrm{Hb}$ response. Prospective trials will be required to confirm whether the presumed higher iron stores achieved in IV ICM-treated patients imply a persistent treatment benefit in women with ongoing menses or subsequent pregnancy.

\section{Conclusion}

Iron deficiency anemia postpartum results in a considerable disease burden. The rapid correction of IDA is of particular interest in severe anemic women declining the need for blood transfusions.

Our findings and the above-mentioned reports show robust evidence of safety and tolerability of IV high-dose iron supplementation with ICM postpartum. Our data further show that ICM has the same efficacy and safety profile in high doses as compared with other IV iron formulations, without the inconvenience of multiple small-dose injections.
High-dose ICM should be the treatment of choice if IV iron treatment is indicated in postpartum anemia.

\section{References}

[1] Auerbach M, Coyne D, Ballard H. Intravenous iron: from anathema to standard of care. Am J Hematol. 2008;83:580-8.

[2] Bailie GR. Efficacy and safety of ferric carboxymaltose in correcting iron-deficiency anemia: a review of randomized controlled trials across different indications. Arzneimittelforschung. 2010;60:386-98.

[3] Bailie GR, Mason NA, Valaoras TG. Safety and tolerability of intravenous ferric carboxymaltose in patients with iron deficiency anemia. Hemodial Int. 2010;14:47-54.

[4] Bashiri A, Burstein E, Sheiner E, Mazor M. Anemia during pregnancy and treatment with intravenous iron: review of the literature. Eur J Obstet Gynecol Reprod Biol. 2003;110:2-7.

[5] Beard JL, Hendricks MK, Perez EM, Murray-Kolb LE, Berg A, Vernon-Feagans L, et al. Maternal iron deficiency anemia affects postpartum emotions and cognition. J Nutr. 2005;135: 267-72.

[6] Bhandal N, Russell R. Intravenous versus oral iron therapy for postpartum anaemia. Br J Obstet Gynaecol. 2006;113: 1248-52.

[7] Bodnar LM, Scanlon KS, Freedman DS, Siega-Riz AM, Cogswell ME. High prevalence of postpartum anemia among low-income women in the United States. Am J Obstet Gynecol. 2001;185:438-43.

[8] Bodnar LM, Cogswell ME, Scanlon KS. Low income postpartum women are at risk of iron deficiency. J Nutr. 2002;132:2298-302.

[9] Bodnar LM, Cogswell ME, McDonald T. Have we forgotten the significance of postpartum iron deficiency? Am J Obstet Gynecol. 2005;193:36-44.

[10] Breymann C. Iron deficiency and anemia in pregnancy: modern aspects of diagnosis and therapy. Eur J Obstet Gynecol Reprod Biol. 2005; 123:3-11.

[11] Breymann C, Richter R. Effectiveness of rhEPO and iron sucrose vs iron therapy only, in patients with postpartum anaemia and blunted erythropoiesis. Eur J Clin Invest. 2000;30:154-61.

[12] Breymann C, Visca E, Huch R, Huch A. Efficacy and safety of intravenous iron sucrose with and without rhEPO for resistant iron deficiency anemia in pregnancy. Am J Obstet Gynecol. 2000;184:662-7.

[13] Breymann C, Gliga F, Bejenariu C, Strizhova N. Comparative efficacy and safety of intravenous ferric carboxymaltose in the treatment of postpartum iron deficiency anemia. Int J Gynecol Obstet. 2008;101:67-73.

[14] Breymann C, Honegger C, Holzgreve W, Surbek D. Diagnosis and treatment of iron-deficiency anaemia during pregnancy and postpartum. Arch Gynecol Obstet. 2010;282:577-80.

[15] Covic A, Mircescu G. The safety and efficacy of intravenous ferric carboxymaltose in anaemic patients undergoing haemodialysis: a multi-centre, open-label, clinical study. Nephrol Dial Transplant. 2010;25:2722-30.

[16] Funk F, Ryle P, Canclini C, Neiser S, Geisser P. The new generation of intravenous iron: chemistry, pharmacology, and toxicology of ferric carboxymaltose. Arzneimittelforschung. 2010;60:345-53.

[17] Geisser P. Pharmakologie und Sicherheitsprofil von EisenCarboxymaltose $\left(\right.$ Ferinject $\left.^{\circledR}\right)$ : Struktur/Reaktivitäts-Verhältnisse von Eisenpräparaten. Port J Nephrol Hypert. 2009;23:11-6. 
[18] Geisser P, Banké-Bochita J. Pharmacokinetics, safety and tolerability of intravenous ferric carboxymaltose: a dose-escalation study in volunteers with mild iron-deficiency anaemia. Arzneimittelforschung. 2010;60:362-72.

[19] Geisser P, Rumyantsev V. Pharmacodynamics and safety of ferric carboxymaltose: a multiple-dose study in patients with iron-deficiency anaemia secondary to a gastrointestinal disorder. Arzneimittelforschung. 2010;60:373-85.

[20] Gozzard D. When is high-dose intravenous iron repletion needed? Assessing new treatment options. Drug Des Devel Ther. 2011;20;5:51-60.

[21] Huch R, Breymann C. Anämie in Schwangerschaft und Wochenbett. 1. Auflage. Bremen: UNI-MED Verlag AG; 2005.

[22] Kersten D, Surbek D. Eisenmangelanämie in der Geburtshilfe. Bedeutung, Differenzialdiagnostik und Therapiemöglichkeiten. Gynäkologie. 2008;3:27-9.

[23] Kociol RD, Newby LK. Ferric carboxymaltose improved symptoms and quality of life in patients with chronic heart failure and iron deficiency. Ann Intern Med. 2010;20;152:JC4-5.

[24] Lyseng-Williamson KA, Keatin GM. Ferric carboxymaltose: a review of its use in iron-deficiency anaemia. Drugs. 2009;69:739-56.

[25] McLean E, Cogswell M, Egli I, Wojdyla D, de Benoist B. Worldwide prevalence of anaemia, WHO Vitamin and Mineral Nutrition Information System, 1993-2005. Public Health Nutr. 2009; 12:444-54.

[26] Milmann N. Postpartum anemia II: prevention and treatment. Ann Hematol. 2012;91:143-54.

[27] Perewusnyk G, Huch R, Huch A, Breymann C. Parenteral iron therapy in obstetrics: 8 years experience with iron sucrose complex. Br J Nutrit. 2002;88:3-10.

[28] Qunibi WY. The efficacy and safety of current intravenous iron preparations for the management of iron-deficiency anaemia: a review. Arzneimittelforschung. 2010;60:399-412.

[29] Schaefer RM, Khasabov NN. The efficacy and safety of intravenous ferric carboxymaltose compared to iron sucrose in haemodialysis patients with iron deficiency anaemia (abstract no. MP375 plus poster). $45^{\text {th }}$ Congress of the European Renal Association and the European Dialysis and Transplant Association, Stockholm. 2008.

[30] Seid MH, Mangione A, Valaoras TG, Anthony LB, Barish CF. Safety profile of iron carboxymaltose, a new high dose intravenous iron in patients with iron deficiency anemia. Blood. 2006; 108:abstract 3739 .

[31] Seid MH, Derman RJ, Baker JB, Banach W, Goldberg C, Rogers R. Ferric carboxymaltose injection in the treatment of postpartum iron deficiency anemia: a randomized controlled clinical trial. Am J Obstet Gynecol. 2008;199:4351-7.

[32] Szczech LA, Bregman DB, Harrington RA, Morris D, Butcher A, Koch TA, et al. Randomized evaluation of efficacy and safety of ferric carboxymaltose in patients with iron deficiency anaemia and impaired renal function (REPAIR-IDA): rationale and study design. Nephrol Dial Transplant. 2010;25:2368-75.

[33] Toblli JE, Cao G, Olivieri L, Angerosa M. Comparison of the renal, cardiovascular and hepatic toxicity data of original intravenous iron compounds. Nephrol Dial Transplant. 2010;25:3631-40.

[34] Van Wyck DB, Mangione A, Morrison J, Hadley PE, Jahle JA, Goodnough LT. Large-dose intravenous ferric carboxymaltose injection for iron deficiency anemia in heavy uterine bleeding: a randomized, controlled trial. Transfusion. 2009;49:2719-28.

[35] Van Wyck DB, Martens MG, Seid MH, Baker JB, Mangione A. Intravenous ferric carboxymaltose compared with oral iron in the treatment of postpartum anemia: a randomized controlled trial. Obstet Gynecol. 2007;110(2 Pt 1):267-78.

The authors stated that there are no conflicts of interest regarding the publication of this article.

Received September 22, 2011. Revised February 5, 2012. Accepted March 6, 2012. Previously published online April 2, 2012. 